\title{
Sciendo
}

DOI: $10.2478 /$ jolace-2020-0011

\section{Establishing a zone of prioritized curricularivity: exploring a critical approach to negotiating multimodal discourses in EFL textbooks}

\author{
Christopher A. Smith \\ Western University, London, Ontario, Canada \\ Csmit655@uwo.ca, christophersmith5@cmail.carleton.ca
}

\begin{abstract}
University English as a foreign language (EFL) programs in expanding circle communities often pressure instructors and students to use globally published EFL textbooks for reasons more socio-political than pedagogical. While some critical studies underscore multimodal discourse to be an under-appreciated source of dominant social narratives in EFL textbooks, few have investigated their live negotiation in classrooms. To address the challenges negotiating potentially harmful social narratives in EFL textbooks, the present study proposes a two-step model for achieving a zone of prioritized curricularivity (ZPC). The model informs reflexive teaching practice in EFL instruction because it necessitates an understanding of a) the curricular commonplaces of a particular EFL program and b) the power and ideologies in the multimodal discourse of their textbooks, to mitigate perceived social injustices in the textbook lessons as they are negotiated "in situ." Demonstrated in vignettes, featuring two EFL courses at Chung-Buk National University in Cheong Ju city, Korea, two instructors used the ZPC framework to inform their reconstruction of multimodal discourses in their EFL textbooks to inculcate student involvement and participation. A novel, multimodal interactional analysis of video recordings looked at proxemics, gaze, spoken language, head movement, auditory emphasis, and gesture and discovered that each instructor recontextualized, neutralized, or skipped much of the multimodal discourse in the lessons. The findings suggest that a ZPC is achieved when the efforts by instructors to recontextualize textbook lessons in situ is met with positive feedback from students in the classroom - noted as heightened attentiveness, happy or cheerful participation, and enthusiastic discussion. The implications suggest a ZPC can help instructors and students and in EFL programs in any expanding circle culture because it can simultaneously improve student learning/acquisition in the classroom, diminish dominant, culturally marginalizing textbook content, while raising the value of student investment in EFL learning.
\end{abstract}

Keywords: EFL learning, EFL textbooks, multimodal discourse analysis, critical curriculum, critical pedagogy, Korean universities 


\section{Introduction}

University English as a foreign language (EFL) programs often pressure instructors and teachers to use generic, globally published EFL textbooks for reasons more socio-political than pedagogical (Chang, 2009). Considering instructors and students need to make the best of matters in EFL under those circumstances, the present study proposes a framework that echoes Fox (2004) arguments that a curriculum is a rhetorical accomplishment. The discursivity to which Fox (2004) refers can be conceptually amalgamated in a term: curricularivity. Curricularivity is additionally informed by arguments supporting critical approaches to EFL learning (i.e., Canagarajah, 2016; Kumaravadivelu, $1999,2006)$. The approach, aimed at finding a zone of prioritized curricularivity (ZPC), encourages reflexive praxis rooted in one's beliefs, assumptions, and knowledge (BAK) about language teaching (Banes, Martínez, Athanases, \& Wong, 2016; Meschede, Fiebranz, Möller \& Steffensky, 2017; Pennycook, 2008; Woods, $1996)$ that any EFL instructor can use for their respective classes. The "zone" was inspired by Rogan's (2007) Zone of Feasible Innovation in curriculum and Vygotsky's (1978) Zone of Proximal Development. In the context of Korean, university EFL courses, the ZPC establishes a "level of potential development as determined through problem solving under guidance" (Vygotsky, 1978, p. 86). Instead of blindly plowing through textbook content, that often serves as the course curriculum in many EFL programs (Richards, 2001; Tomlinson \& Masuhara, 2011), without concern for one's students, who may feel culturally marginalized by lesson contents that can be counter-intuitive to their cultures (i.e., Song, 2013; Weninger \& Kiss, 2013), instructors can recontextualize textbook content to raise the value of student language learning investment. However, as Fredricks (2007) notes in their application of culturally relevant alterations to EFL textbook content, a systemic framework would greatly improve the reflexive praxis that most instructors do internally when negotiating textbook content in EFL classes. This study endeavors to address that gap in EFL teaching practice.

\section{Textbooks and EFL education in Korean Contexts}

A Foucauldian perception of education argues that it is a "management of populations" (Ball, 2012, p. 6) that shapes social reality and enables "state" control wherever that education is received (Althusser, 1971). By extension, school textbooks are artifacts of that management because they are preceded by the adjective "school" (Curdt-Christiansen \& Weninger, 2015), which validates the social norms they project. In the context of the present study, the unquestioned use of EFL textbooks and the lack of critical attention to their multimodal contents is problematized because poorly considered classroom delivery of their lessons can present challenges for Korean university students, resonating with a complex web of issues revolving around EFL learning in Korean society (i.e., Adams \& 
Gottlieb, 2017; Ahn, 2011; Chun, Kim, Park, McDonald, Oh, Kim, \& Lee, 2017; Song, 2013; Thompson \& Lee, 2018).

Although the ZPC framework is designed to be suitable for any expanding circle culture with EFL programs, we will look closely at Korean post-secondary contexts because of the vignette that demonstrates the use of the framework "in situ." For Korean students, much like EFL students elsewhere, learning English is a socioeconomic investment and an attractive commitment to political stakeholders involved with post-secondary education policy at the national level (Ahn, 2011; Canagarajah, 2016; Song, 2013). However, some university EFL programs promote a language learning curriculum that 1 ) inhibit creative or spontaneous expression, 2) deny student involvement as informative to the syllabus, and 3) adhere to seemingly antiquated methodological or theoretically established principles that overlook any other language learning phenomenon (Paik, 2018; Stoller, 2015). Relatedly, the test-driven learning outcomes that Korean university programs expect their instructors to achieve do little to foster deeper learning and functioning knowledge to inform live communication in English (Biggs \& Tang, 2007; Paik, 2018; Stoller, 2015). For Biggs and Tang (2007), declarative knowledge has been the traditional hallmark of university education, where students come to (literally) be indoctrinated with knowledge. While it may seem that this study implies a preference to functioning over declarative knowledge, the intention here is to note the latter outweighs the former in Korean university EFL curriculums to meet state-sanctioned evaluations, such as the secondary school "su-neung" or Korean SAT (Ahn, 2014; Haggerty \& Fox, 2016). The result is a Korean graduate who knows, for example, what a subjunctive verb form is, but not be able to say "I wish I were able to speak better English" in a casual conversation. While some research addresses these challenges for EFL teaching practices, by integrating student needs (i.e.), program requirements and teacher expertise to nurture functional knowledge (Biggs \& Tang, 2007), in Korean contexts, many stall under the weight of academic stakeholders, such as deskilled instructors following pre-set learning outcomes, the Korean Institution for Curriculum and Education (Haggerty \& Fox, 2016), or other federal entities fiscally connected to postsecondary institutions (Ahn, 2011). To address these challenges, the ZPC proposed in the present study may initiate a cultural "fracturing" of fossilized pedagogical practices (i.e., Benson, 2017; Ellis, 2017) because it inspires the transformative refinement (Rabbidge, 2017) of a curriculum, inclusive of teacher expertise (Banes, Martínez, Athanases \& Wong, 2016) delivering textbook content, towards deeper learning in Korean university EFL classrooms.

Much like K-12 EFL instruction, native-English speaking university instructors are expected to speak only English during class and students are expected to use Korean only if necessary (Thomson \& Lee, 2018). Additionally, the classes are expected to follow the syllabus of the chosen textbook and use the digital- 
interactive supplemental activities for homework exercises. Most of the activities in Top Notch 2 (Saslow \& Ascher, 2011) decontextualize the English components into formulaic lists of expressions that are supposed to represent passable live speech and students are expected to negotiate those contents in class as instructed (Curdt-Christiansen \& Weninger, 2015). The innovation of practice featured here underscores the observed results of student activity, participation, and performance. The ZPC was applied to reconstruct presentation and negotiation of textbook lessons towards more culturally intuitive, multimodal contexts for Korean students.

As we will see in the description, the ZPC changed the way the instructor used the multimodal discourse in the textbook lessons so that any instances of racial othering, cultural marginalization, or Anglo-centric hegemonies were diminished under the preferred agency of Korean contexts without digressing from the linguistic challenges of the lessons. The premise that textbook content was not enjoyable was presented to the students, who heartily agreed, then altered in situ as the instructor moved from one activity to the next. The intention of this approach was meant to foster deeper learning in EFL by giving Korean students a stronger L2 English identity in the recontextualized content.

\section{Textbooks in Korean EFL contexts}

A school textbook, according to Dendrinos (2015), is afforded legitimacy because it follows the adjective school. That legitimacy, Dendrinos (2015) argues, gives a measure of value to content that helps construct realities to which the students anchor their own. In the contexts of language learning, those realities have the power to "other" economically disadvantaged students or portray nonEnglish speaking global citizens as members of less important communities (Canagarajah, 2016; Dendrinos, 2015; Fitzgibbon, 2013; Song, 2013). In so doing, these publications fail to nurture an appreciation for cultural difference and foster a greater sense of otherness (Van Dijk, 2011) that may harm an L2 learner's educational experience (Dendrinos, 2015; Pennycook, 2008).

As noted, instructors and students in Korean university EFL programs are pressured to used generic textbooks by their respective departments (Chang, 2009). EFL textbooks, despite now being sold as hybridized hard copies with digital, multimedia components of supplemental material (Bell \& Gower, 2011), have changed little in terms of projecting certain innercircle ${ }^{1}$ (Kachru, 1992) social realities against which all other cultures are judged (Curdt-Christiansen \& Weninger, 2015; Song, 2013). In an expanding circle nation, such as Korea, globally published EFL textbook packages are still a popular choice for post-secondary English courses but, in most cases, that choice was not made by the instructor or the student (Ahn, 2014; Paik, 2018). If one subscribes to Van Dijk (2011) insistence that, in textbooks, what passes for knowledge is often ideologically founded, then 
it is surprising that few critical studies of EFL textbooks draw attention to the multimodal discourse because the images and text in the lessons become one in a Gestaltian field of meaning (Bateman, 2014; Machin \& Mayr, 2012) that supports the social realities to which Curdt-Christiansen and Weninger (2015) refer. Considering some of the research that points to inner circle hegemonic narratives that marginalize the cultures of their intended audiences, this innovation of practice is meant to diminish those harmful narratives in the multimodal discourse of their EFL textbooks, while improving student interest, motivation, performance, and participation in their university programs.

\section{A Zone of Prioritized Curricularivity}

The procedure for establishing a ZPC is illustrated in the following two steps.

\section{Step 1: Establishing the curricular commonplaces}

Informed by Connely and Clandinin (1988) and Null (2016), the curricular commonplaces include textbooks because of their significance as pedagogical artifacts in Korean, post-secondary EFL programs (Fitzgibbon, 2013). Table 1 features a series of questions the instructor must answer to the best of their ability before moving on to Step 2.

\begin{tabular}{|l|l|}
\hline Subject & $\begin{array}{l}\text { In the context of the EFL culture, what are the most common } \\
\text { learning outcomes or challenges during study? Why is the } \\
\text { subject consequential to Korean society? }\end{array}$ \\
\hline Milieu & $\begin{array}{l}\text { Who are included in the academic milieu? What concerns do they } \\
\text { have with the EFL culture and how do they affect it? }\end{array}$ \\
\hline Students & $\begin{array}{l}\text { What is the relationship between the students and the EFL } \\
\text { culture? What is their level of competency? What motivations or } \\
\text { demotivators do they have in the EFL culture? }\end{array}$ \\
\hline Teachers & $\begin{array}{l}\text { Who are you, in relation to the EFL culture? How are you trained } \\
\text { to teach EFL? What are your BAK (Woods, 1996) about EFL } \\
\text { learning in this culture? }\end{array}$ \\
\hline Textbook & $\begin{array}{l}\text { What textbook was chosen for the EFL course and by whom? Is } \\
\text { it an effective choice for the subject? How do you, the milieu, and } \\
\text { the students feel about using it? How much of it must be used to } \\
\text { fulfill a prescribed syllabus? }\end{array}$ \\
\hline
\end{tabular}

Tab. 1: Step 1: Concerns of Curricular Commonplaces in Korean University EFL Programs

Note. Step 1 in achieving a zone of prioritized curricularivity. 
Fairclough (2013) reminds us that context is key to unveiling insidious models of domination and social injustice. Hence, it is imperative that instructors achieve some measure of understanding about the curricular commonplaces in a course of study, such as English Communication at Chung-Buk National University, where the vignettes, detailed later in this study, take place. Having established some answers to those questions in Table 1, an instructor can turn their attention to the multimodal discourse of the lessons and find answers to the questions in Table 2.

\section{Step 2: Establishing power relations and ideologies in multimodal discourse}

The critical framework illustrated in the Table 2 were informed by multimodal critical discourse analysis frameworks from Kress \& Van Leeuwen (2006), Machin and Mayr (2012), and Wodak and Meyer (2016). This framework encourages the instructor to look closer at the social realities that perpetuate instances of hegemony or dominant narratives in the multimodal discourse of their EFL textbook lessons.

What are the spatiotemporal and sociocultural contexts of the lesson?

Who is afforded agency in the multimodal discourses?

What is the purpose of the lesson? Could it be counter-intuitive to a Korean student?

What is denotated in the lesson? What does the denotation appear to teach?

Do any visual elements emphasize or de-emphasize any aspect of lesson?

What are the structures of social reality? Are they relative to Korean contexts?

What symbols, signs, or recurring patterns support the social narratives?

What are the connotations in lessons?

What are the multimodal silences? What appears to be missing from the lesson?

How is power supported, challenged or concealed?

Tab. 2: Step 2: Multimodal Critical Discourse Analysis for EFL Textbook Lessons Note. Step 2 in achieving a zone of prioritized curricularivity.

The present study presumes a ZPC accomplishes two objectives: informing the instructor of the curricular commonplaces that are consequential to EFL learning for that particular discourse community (i.e. Scollon, Scollon, Jones, 2011) and encouraging the instructor to look critically at the textbook content for instances of racial or social marginalization, othering (i.e. Van Dijk, 2011), or diminished agency (to name only a few items) and how those instances of social injustice can be recontextualized, as per the curricular commonplaces of the target audience in a course of study. Hence, the present study asks: Does an instructor's understanding of curricular commonplaces, on the one hand, and power relations and ideologies in 
the multimodal discourse of their textbooks on the other, appear to help them achieve a ZPC in their classes? How do their students respond?

\section{Methods}

The ZPC framework, illustrated in the previous section, is an amalgam of two parts: 1) establishing the curricular commonplaces of the course of study and 2) establishing what features of the textbook either support or appear counterintuitive to the commonplaces of that course of study. However, this section features a method for measuring how the instructor negotiates or reconstructs lessons from their textbook in situ. In other words, the framework featured in the Data Analysis encourages the instructor to consider: in the context of "this" EFL classroom and given what I have learned by following the steps prescribed in the ZPC, how do I negotiate or recontextualize the lessons with my students to minimize any perceived social injustice in the lesson contents? These considerations not only ask the instructor to consider "what is said" and "how it is said" (Gee, 2004) in their textbooks, but also "what is seen" and "how it is seen" (Machin \& Mayr, 2012; Kress, 2010), so we need to include a brief note about multimodality and discourse analysis.

\section{Multimodal critical discourse analysis}

From the early 1990's research in methods of discourse analysis by Teun van Dijk, Norman Fairclough, Gunther Kress, Theo Van Leeuwen, and Ruth Wodak, critical discourse analysis (CDA) was partially inspired by critical social inquiry and critical linguistics, aimed at underpinning ideological characteristics in linguistic processes of discourse (Fairclough, 2013; Sheyholislami, 2001; Wodak \& Meyer, 2016; Van Dijk, 1997). By bringing criticality to language analysis, CDA "merges a concentrated focus on discourse with social elements such as power relations and ideologies" (Fairclough, 2013, p.7). Considering that CDA is not a neatly contained method but a "problem-oriented interdisciplinary research movement, subsuming a variety of approaches, each with different theoretical models, research methods and agenda" (Van Dijk, 2011, p.357). Multimodal CDA, asks the same questions but acknowledges discourse as something beyond linguistic means to include visual semiotics, such as color, shape, composition, iconography and how those inventories emphasize or de-emphasize certain narratives in multimodal ensembles (Kress \& Van Leeuwen, 2006; Machin \& Mayr, 2012). 


\section{Results}

\section{A vignette in Korea}

The following observations highlight how Instructor A and B interpreted the ZPC framework and used it to inform their recontextualization of the multimodal discourse in situ as they negotiated the lesson activities of Top Notch 2 (Saslow \& Ascher) (see Figure 1).

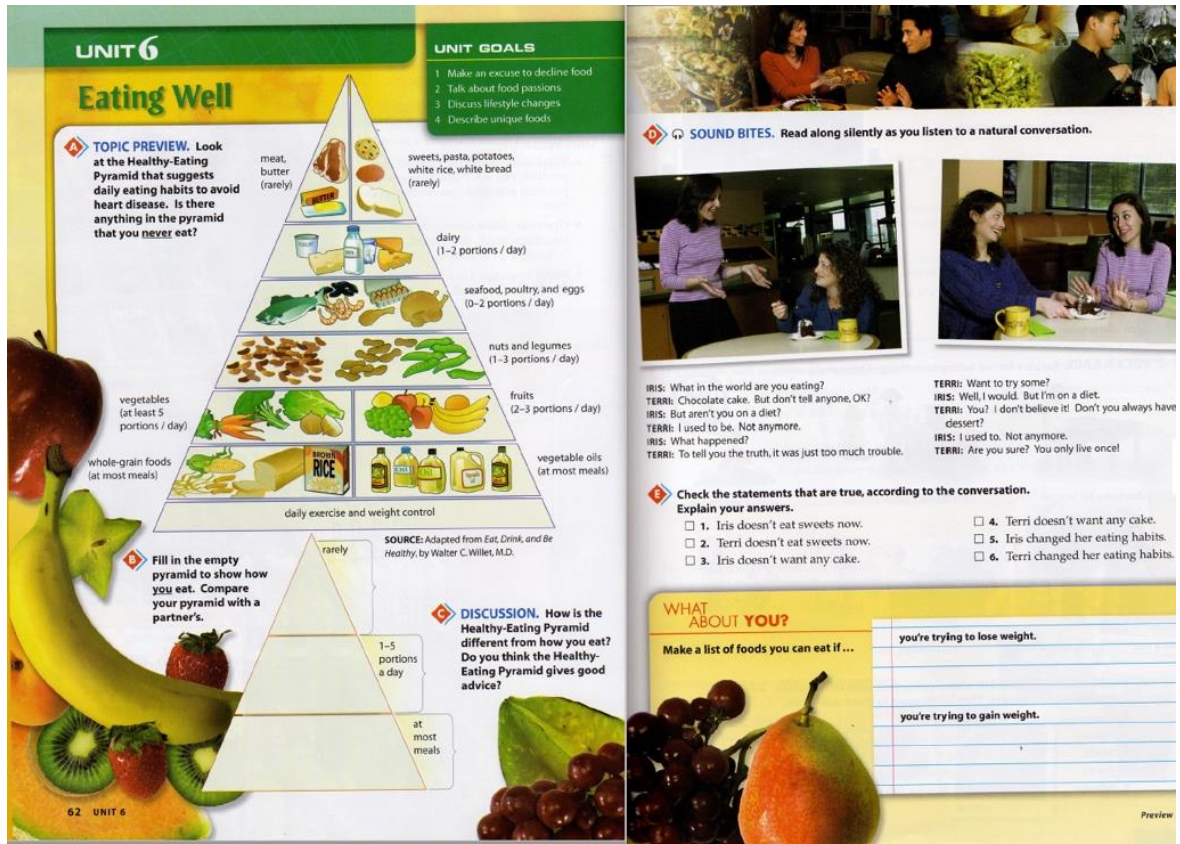

Fig. 1: Unit 6, Top Notch 2 (pp. 62-62).

\section{Instructor A's Class}

Instructor A presents the topic material in the exact progression of the textbook unit but does not include or focus on the visual discourse in the book or provide his own. Alternatively, he challenges the students to imagine situational or contextual metaphors. For example, he notes that while one glass of wine may be considered part of a healthy diet, 100 glasses of wine is not. Student response is positive to his exaggeration and they respond collectively with laughter at the notion. In this way, Instructor A chose to focus on meaning and introduce habits while avoiding specific multimodal reference in the textbook. The focus on habits, served both as an icebreaker and a segue into the textbook's lesson about food or 
dietary habits. The students appeared fully engaged and eagerly joined what seemed to be an impromptu discussion about good habits and bad habits.

Instructor A diminishes the agency of some multimodal discourse in the textbook by pointing to the food pyramid (see Figure 1) and noting "I remember other Korean students teaching me that this is referred a food pagoda...is that correct?" Instructor emphasizes pagoda to which many students respond by nodding and saying yes in unison. They appear happy to disregard the agency of the food pyramid and enjoy a shared cultural experience with the instructor. Hence, while the textbook content appears to guide Instructor A's linguistic topical choices, insofar as a peripheral reference, it does not aid the cultural relevance of the lesson.

Instructor A makes the visual content relevant to his students by presenting all lessons from a Korean perspective. At one point, Instructor A asks: "are you a big sam-gyeop-sal (Korean BBQ bacon lettuce wrap) eater?" to demonstrate how someone might use the expression "I'm a big..." to which they would attach something they like very much. In this case, while the textbook activity (see Figure 2) uses many dietary examples, all identifiable with inner-circle cultures, the students do not respond eagerly, and mumble amongst themselves quietly without much discussion. However, as soon as Instructor A says, "I'm a big sam-gyeop-sal eater", the students immediately laugh and engage in happy discussion with each other, expression they are "big something eaters", but without giving the textbook much attention. These are some examples of how the contents of the lesson were enhanced by the educator to include a Korean perspective but diminish to contextual agency of the multimodal discourse. The students, in all cases, appeared to be very attentive and receptive to those alternatives.

\section{Instructor B's Class}

Overall, Instructor B followed the textbook syllabus and the lessons quite closely. However, in almost every situation, he provided alternative contexts for the lessons. For example, after carefully reviewing the food pyramid, featured in Figure 1, he asked if everyone was sufficiently rested and feeling healthy, then asked if that was due to a diet reflective of the food pyramid's recommendations. Students respond with laughter because much of the food featured in the pyramid would be "foreign" to the students and in some cases unrecognizable. To the researcher, these subtle digressions inspired more classroom discussion and participation. In any of the cases where Instructor B was drawing attention to any of the visual discourse, it was only to draw considered attention to its connection to the linguistic components. For the most part, student response to the silencing of the visual discourse was attentive and engendered active participation 
whenever Instructor B initiated discussion with supplemental lexical items he often wrote on the whiteboard.

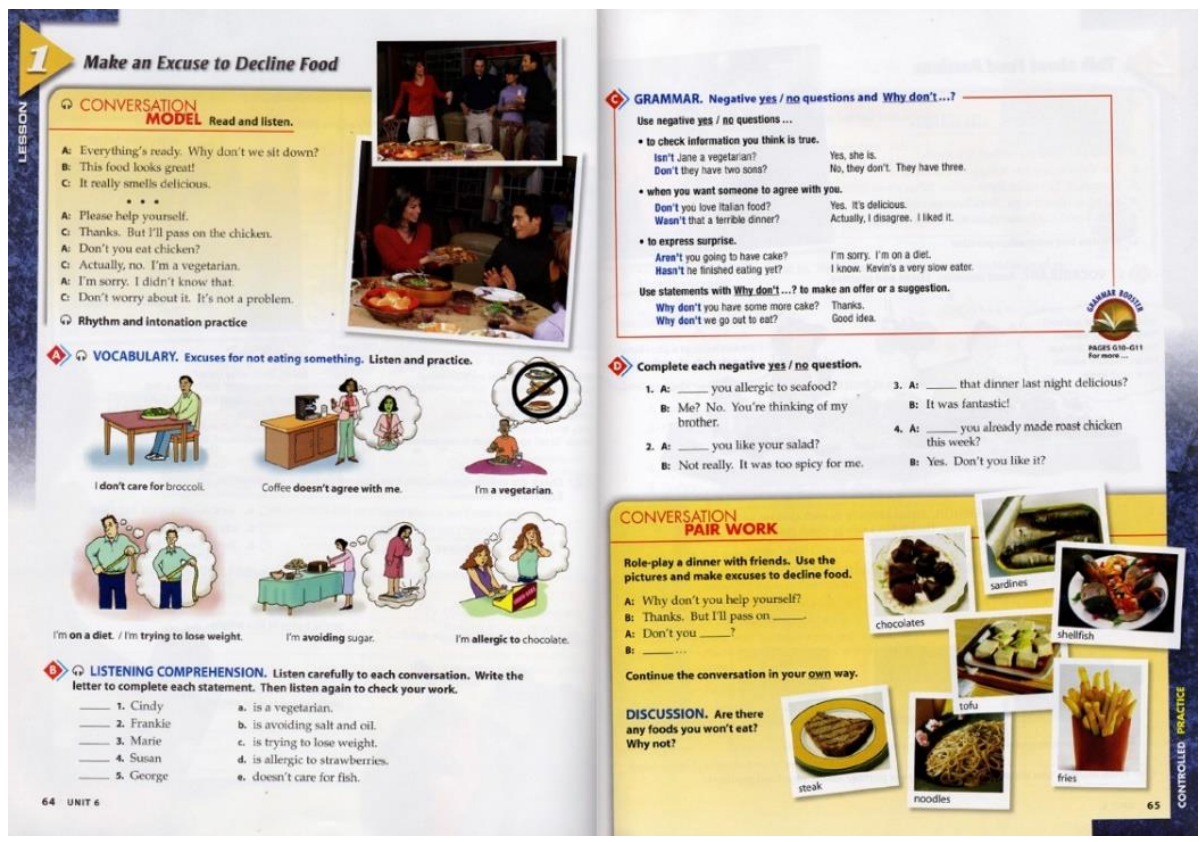

Fig. 2: Unit 6, Top Notch 2 (pp. 64-65).

Instructor B underpins a cultural contradiction by noting that rice, a daily staple of Koreans, is listed in the same category of portion control as pasta or potatoes. Apparently anticipating the potential for social marginalization, considering rice is a Korean staple, Instructor B prioritized a Korean perspective noting an item on the food pyramid but using the Korean word "kong-na-meul" (soybean) to connect students to it. Student response was an audible and collective "ahhh!" and the cultural relevance of that label must have sufficiently connected the students to the lesson because the discussion that followed was the loudest point in the class.

By using the definite article (the) before a constructed form of social reality (food pyramid), it become a standard of measurement rather than an example of how some other people eat (Machin \& Mayr, 2012). The endorsement of the medical physician, lower right, under the pyramid (see Figure 1) legitimizes that 
forced agency. Hence, both instructors identified it as counter-intuitive to Korean culture.

In Korean culture, politeness manifests in many ways, such as in certain suffixes used when speaking with people of higher or lower social status in society (i.e., elderly or children). When addressing polite ways to refuse food, Instructor B uses a Korean cultural perspective to situate the lesson. He notes a common Korean misconception that English does not have honorifics, such as specific kinds of suffixes in Korean, used when speaking to those of higher social status. He says English may not have the same kinds of linguistic aspects to polite speech as Koreans have, but English speakers do have some version of that. He reminds the students: “...if you say, broccoli sucks! that's really strong...banmal!" (Korean, meaning friend speech). Here he uses the Korean word to emphasize the point that the notion of politeness is an accessible aspect of English to which they can apply their L1 contextual understanding. He continues: "...so you might want to say I don't care for broccoli ...it sounds nicer and is less harsh." Here, Instructor B has situated a portion of English dialogue in a Korean context and used specific words like jon-daet-mal (polite speech) and ban-mal (slang or friend speech) to delineate the English forms of politeness. Student response is very expressive at this point. There are audible gasps, heads nodding, and one female student echoes what many are collectively saying: "Aha! I see that now!" The atmosphere of the class became noticeably louder and students engaged in enthusiastic discussion when they realized how communicative politeness translates into English.

\section{Analysis}

A series of high-inference questions (Dornyei, 2007), detailed in Table 3, underpinning the nature of the EFL textbook use in class served as key points of observation in the analysis of the video recordings. The questions listed in Table 3 were partially inspired by mediated discourse analysis (Scollon et al, 2011) and studies of action-oriented approaches to multimodal interactional analysis for classroom observations and examinations of video recorded transcriptions (Cortez, 2008; Jewitt, Bezemer, \& O'Halloran, 2016; Norris, 2019; Scollon, Scollon, \& Jones, 2011; Wohlwend, 2011).

By endeavoring to answer these questions (Wohlwend, 2011), the researcher notes "how actions are made meaningful and social in situ rather than in representation, looking at interaction...semiotic practices, and discourses in contexts" (Wohlwend, 2011, p. 3). 
1. Does the instructor present the lesson to students as it is presented in TN2? How are the students responding?

2. Does the instructor provide alternative visual or metaphoric reference in lieu of the content? How did the students respond?

3. Does the instructor change any part of the lesson? How did the students respond?

4. How does the instructor present any of the visual aids or speak of any of the images in the lesson? How did the students respond?

5. Does the genre of the multimodal content in the textbook appear to represent and aid the linguistic and cultural relevance of the lesson? How are the students responding to this?

6. Does the multimodal content appear counter-intuitive to Korean culture? If so, is this manifesting in the discourse of instruction or in the student negotiation of the content?

7. Does the instructor make the linguistic and cultural references relevant in a Korean context during classroom discourse? Do the students appear confused or accepting of the content?

8. Are there any uncomfortable silences in the classroom discourse? Does this appear related to the content of the textbook or the negotiation of the content?

9. What were the physical or behavioral responses while negotiating the content? Did any auditory (i.e.: speech), visual (i.e.: gaze), action (i.e.: gesture, posture, movement, facial expression, or touch) or environmental (i.e.: proxemics) signifiers or peculiarities appear among the students or the instructor during the lesson?

10. How did the students and instructors relate to the visual components of the lesson in TN2? Does the multimodal content appear familiar, strange, or dismissed as unimportant to the lesson? How and why was this noticed?

Tab. 3: Multimodal Interactional Analysis for an EFL Classroom

\section{Discussion}

Born from personal classroom observations of student resistance, transformation, appropriation, or neutralization (Cortez, 2008) of multimodal discourse in the researcher's own EFL courses, the ZPC serves as a preliminary aid for EFL instructors in expanding circle English language learning programs to use textbook content in their classes. The ZPC, used by both instructor's in the featured vignette unites frameworks of multimodal critical discourse analysis (i.e., Machin 
\& Mayr, 2012) and theoretical princeps of curricular commonplaces (i.e., Connely \& Clandinin, 1988; Null, 2016) to assist EFL instruction in courses that lean heavily on the use of a chosen textbook. In the context of Korean post-secondary EFL courses, the lessons presented by each instructor were informed by an established ZPC. Using that new foundation, lessons were built by recontextualizing, rewriting, or avoided certain multimodal contents to better serve the interests of Korean university students who may feel marginalized by the forced consumption of certain social realities in globally published EFL textbooks (Curdt-Christiansen \& Weninger, 2015; Chang, 2009; Song, 2013).

Overall, Instructor A and B have a similar approach to presenting the textbook content in class. Each transform the content by using comical allegory, cultural translation, personal engagement, or careful explanation of why particular linguistic highlights or omission of the multimodal discourse in Top Notch 2 (Saslow \& Ascher, 2011) might be important to English speakers. Additionally, both instructors appear to make some effort to explain why the students should know those perspectives without pressuring them to abandon Korean cultural values or norms. These adjustments to textbook material and the manner that they were negotiated in class suggests that each instructor was informed by their understanding of the curricular commonplaces of Korean university EFL programs and the dominant social realities in the multimodal discourse of Top Notch 2 (Saslow \& Ascher, 2011).

\section{Negotiating the curricular commonplaces}

In their respective classrooms, Instructor A and B exhibited an understanding of the curricular commonplaces of Korean post-secondary EFL learning (see Table 1), such as the subject, milieu, students, teachers, and the textbook. Each managed time by ensuring a constant, unimpeded flow of classroom activity, especially when deviating from the textbook to draw attention to linguistic variation. In this way, they ensured the value of student investment in EFL learning while meeting the expectations of Korean institutional milieu of EFL programs, who want students to use globally published EFL textbooks (Chang, 2009; Fitzgibbon, 2013). Each instructor appears to use their BAK (Woods, 1996) to omit, change, recontextualize, or joke about the multimodal discourse in the lessons of Top Notch 2 (Saslow \& Ascher, 2011), such as asking students if one glass of wine or 100 glasses of wine / day is healthy, holding the textbook and standing close to students to present co-engagement with the material (see Figure 3), omitting visual discourse of the lessons while concentrating on the linguistic challenges, presenting lesson content from student perspectives, inspiring students to be critical of EFL materials, and to accept that one's identity as a Korean university student should not be diminished in the process of consuming the multimodal discourse of a globally published EFL textbook. 


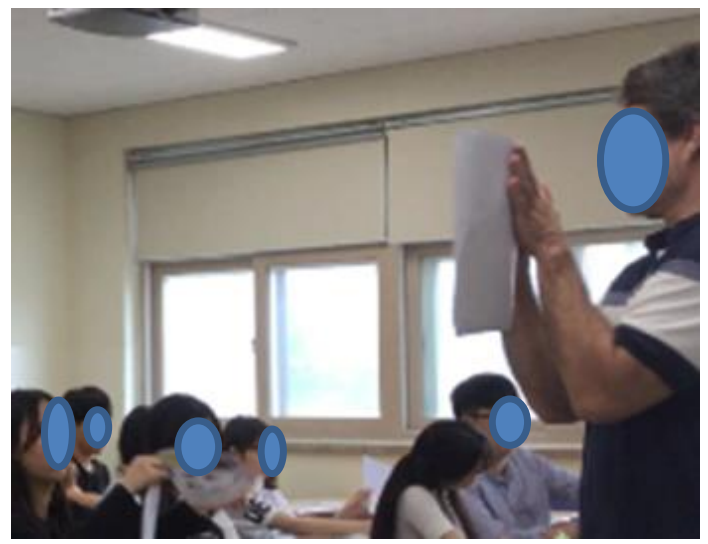

Fig. 3: Instructor B co-engagement with textbook material

\section{Negotiating dominant social narratives in the textbook}

Each instructor appeared to prepare for the use of Top Notch 2 in their classes by using Step 2 in the ZPC for critically analyzing the multimodal content. Their reconstruction of the lessons may have been inspired by the narrow or one-sided representation of certain social realities. For example, most of the students in each of the classes did not have much interest in examining the food pyramid (see Figure 1), likely because it does not reflect a Korean diet, even though it was emphasized in size, composition, and detail, with an endorsement from a published physician. That superior agency of a "Western" diet, presented as the standard against which all other cultures are measured, may have been noted by each instructor, who chose to transform the food pyramid into a "food pagoda," to which students responded with laughter as they reconstructed the items in lively discussion.

Instructor B may have noticed that the food pyramid featured in Unit 6 overshadowed the smaller one that students needed to fill in (see Figure 1) because he gave a detailed explanation of the former's contents as if to highlight that students were not expected to see that device as a standard against which Korean culture was to be measured. Instead, he pointed out the areas where legumes and rice were (two items important to Korean culture) and discussed with the students why they were important.

Each instructor skipped some sections and included the students in the decision, simultaneously avoiding multimodal content that he perceived as inhibitive to EFL learning or culturally marginalizing to Korean university students, while empowering them in the consumption of EFL learning materials. 


\section{A Zone of Prioritized Curricularivity}

It is important to remember that achieving a ZPC is partially informed by Fox (2004), who argued that a curriculum is a rhetorical accomplishment. In the context of the present study, that accomplishment is reflected in student reception, consumption, and perceived acceptance of the instructor's efforts to negotiate the multimodal discourse of their globally published EFL textbook. In other words, the present study underscores not only what is or is not taught, but how it is or is not taught. The term "curricularivity" underscores the discursivity of a curriculum and marks the benefits of considered, negotiated classroom discourse; in this case, the multimodal discourse of Top Notch 2 (Saslow \& Ascher, 2011).

In most cases, students were often and initially confused about the lessons, as evidenced by their silence or their facial expressions as they quietly tried to understand the lessons but appeared relieved when the instructors transformed the content to appeal to students' sociocultural norms. That focus on recontextualization was met by students with heightened attentiveness and more robust classroom discussion.

Student response was fully attentive and amenable whenever an instance of personal reflection added to the classroom commentary. They appeared to enjoy sharing Korean experiences with each of the instructors. Student response and participation perceptibly rose whenever the instructors initiated Korean perspectives, such as talking about Korean alcohol or popular pub food. During these exchanges, students appeared more willing to exchange dialogue with neighbors at their tables and the atmospheric volume of the classroom increased. Overall, in each of the classes, there appeared to be many expressions of bemused curiosity about the Unit's topic of food, illustrated from a non-Korean perspective. Students did not engage any of the content outside of direct instruction.

In each of the classrooms, it is obvious that each professor had a profound knowledge of Korean contexts and the curricular commonplaces (Connely \& Clandinin, 1988) of Korean university EFL. This is evident in their respective, effortless transformations of the multimodal content to suit the needs of their students. By following the content page by page, they are adhering to the restrictive curriculum most universities follow but doing so in a way that exercises reflexivity in the negotiation of the textbook content, while fostering a functional knowledge of the linguistic challenges (Stoller, 2015).

The present study asks if an understanding of curricular commonplaces, on the one hand, and the dominant social realities in the multimodal discourse of EFL textbook lessons, on the other, can help instructors achieve a ZPC. The findings suggest that student response to instructor's negotiation of the textbook was certainly more positive than using the lessons unchanged. By observing how students and instructors resist, transform, appropriate, or neutralize (Cortez, 2008) any of the multimodal content in classroom negotiation, it appears that the 
instructor efforts, informed by the ZPC framework proposed in this study, inspires a more enjoyable delivery system for textbook content that may result in a deeper learning or functional knowledge of English (Stoller, 2015).

\section{Caveats and Future Studies}

The data in the study may appear limited because the classes are quite short. Overall, the video recording lasted only one hour for each of the studies. It is possible that an ethnographic analysis or a longitudinal study might yield more salient results but there are complicated, logistical restrictions, enforced by administrative milieu, that deter such studies in Korean university EFL classrooms. Nevertheless, this study recommends such avenues of research need to be further explored. Additionally, the video recording did not yield as many facial expressions and body language as anticipated so some of the assertions in the discussion and the findings are sourced in the researcher's own observations and notes while watching the classrooms via video feed during the lessons.

\section{Conclusions}

This study proposed that a ZPC in Korean university classrooms can be achieved by understanding the curricular commonplaces of Korean EFL learning and the power and ideologies in the multimodal discourse of the chosen textbook for those programs. However, whether students are Korean, Jamaican, or Chinese, (i.e., Kuck, 2007; Kutz, 2004; Cortazzi \& Jin, 1993), fears of identity loss, feelings of awkward social positioning, or senses of "outsiderness" are very real challenges that some L2 learners face. Therefore, the framework for a ZPC could be used in any expanding circle culture (Kachru, 1992). A ZPC encourages instructors to use their BAK (Woods, 1996) of language learning to ask questions about the curricular commonplaces and dominant narrative in textbook content. The vignette demonstrated that in a restrictive curriculum, such as in Korean universities, where a large percentage of classroom activity should be based on textbook material, the instructors were able to manipulate the multimodal discourse in their textbook lessons using the ZPC framework by making lessons relevant to the curricular commonplaces of the university EFL program and finding social alignments to the lessons that diminished dominant narratives in Korean culture. In other words, the ZPC helped instructors increase the value of their students' investment in EFL learning. Moving forward, studies that use a ZPC in other expanding circle cultures might provide further evidence of its usefulness informing EFL instructional practices.

Textbooks in Korean EFL learning contexts are shown to be artifacts of the rhetorical accomplishment to which Fox (2004) implies as the discursivity of a curriculum. That discursivity is sourced in an instructor's fluency with the curricular commonplaces and dominant social narratives in the multimodal 
discourse of their EFL textbooks. Hence, a ZPC informs the instructor how to transform textbook content for multiple curricular registries. Student response to instructor's efforts to re-purpose lesson contents was physically and emotionally perceptible, indicated in their engagement of robust discussion with neighbors, happy facial expressions, and active notetaking during lectures. For these reasons, we believe a ZPC contributed to the overall atmospheric sense of accomplishment at the end of each class.

\section{Acknowledgment}

I wish to thank Professor Dale Marcelle and Professor Audwin Wilkinson and the participating students at Chung-Buk National University, Korea.

\section{References}

Adams, D., and Gottlieb, E. E. (2017). Education and social change in Korea. Routledge.

Ahn, K. (2011). Conceptualization of American English native speaker norms: A case study of an English classroom in South Korea. Asia Pacific Education Review, 12, 691-702. https://doi.org/10.1007/s12564-011-9169-6 Ahn, H. (2014). Teachers' attitudes towards Korean English in South Korea. World Englishes, 33(2), 195-222. https://doi.org/10.1111/weng.12081

Althusser, L. (1971). Ideology and ideological state apparatuses. Lenin and philosophy and other essays. Trans. Ben Brewster. New York: Monthly Review Press, 1270186.

Ball, S. J. (2012). Foucault, power, and education. Routledge.

Banes, L. C., Martínez, D. C., Athanases, S. Z., \& Wong, J. W. (2016). Self-reflexive inquiry into language use and beliefs: Toward more expansive language ideologies. International Multilingual Research Journal,10(3), 168-187. https://doi.org/10.1080/19313152.2016.1185906

Bateman, J. (2014). Text and image: A critical introduction to the visual/verbal divide. Routledge.

Bell, J., \& Gower, R. (2011). Writing course materials for the world: A great compromise. In Tomlinson, B. (Ed.), Materials development in language teaching (2nd ed., pp. 135-150). Cambridge: Cambridge University Press.

Benson, P. (2017). Language Learning Beyond the Classroom: Access all Areas. Studies in Self- Access Learning Journal, 8(2).

Biggs, J., \& Tang, C. (2007). Teaching for quality learning at university. Berkshire. England: McGraw-Hill, Date retrieved: August 5, 2014.

Canagarajah, S. (2016). TESOL as a professional community: A half-century of pedagogy, research, and theory. TESOL quarterly,50(1), 7-41. https://doi.org/10.1002/tesq.275 
Chang, B. M. (2009). Korea's English Education Policy Innovations to Lead the Nation into the Globalized World. Journal of Pan-Pacific Association of Applied Linguistics, 13(1), 83-97.

Chun, S., Kim, H., Park, C. K., McDonald, K., Oh, S. H., Kim, D. L. \& Lee, S. M. (2017). South Korean students' responses to English-medium instruction courses. Social Behavior and Personality: An international journal, 45(6), 951965. https://doi.org/10.2224/sbp.6049

Connelly, F. M., \& Clandinin, D. J. (1988). Teachers as Curriculum Planners. Narratives of Experience. New York: Teachers College Press.

Cortazzi, M., \& Jin, L. (1993). Cultures of learning; language classrooms in China (pp. 169-206). Society and the Language Classroom. Cambridge, UK: Cambridge University Press.

Cortez, N. (2008). Am I in the book? Imagined communities and language ideologies of English in a global EFL textbook. (Unpublished doctoral dissertation). University of Arizona. http://hdl.handle.net/10150/195553

Curdt-Christiansen, X. L. and Weninger, C. (Eds). (2015). Language, ideology and education: The politics of textbooks in language education. Routledge.

Dendrinos, B. (2015). The politics of instructional materials of English for young learners. In Language, Ideology and Education (pp. 43-63). Routledge.

Dörnyei, Z. (2007). Research methods in applied linguistics: Quantitative, qualitative, and mixed methodologies. Oxford University Press.

Ellis, R. (2017). Oral corrective feedback in L2 classrooms: What we know so far. In: Corrective feedback in second language teaching and learning (pp. 3-18). Routledge. https://doi.org/10.4324/9781315621432

Fairclough, N. (2013). Critical discourse analysis: The critical study of language. Routledge. Doi: 10.4324/9781315834368

Fitzgibbon, L. (2013). Ideologies and power relations in a global commercial English language textbook used in South Korean universities: A critical image analysis and a critical discourse analysis. Unpublished $\mathrm{PhD}$ dissertation. University of Queensland.

Fox, J. (2004). Curriculum design: Does it make a difference. In Contact, Special Research Symposium Issue, (30)2, 1-5.

Fredricks, L. (2007). A rationale for critical pedagogy in EFL: The case of Tajikistan. The Reading Matrix, 7(2).

Gee, J. P. (2004). An introduction to discourse analysis: Theory and method. Routledge. Doi: 10.4324/9780203005675

Haggerty, J. and Fox, J. (2016). Test intensity, language testing experience, and the motivation to learn English in South Korea. In: Arayadoust, V. \& Fox, J. (Eds.), Trends in language assessment research and practice: The view from the Middle East and the Pacific Rim (pp. 486-512). Newcastle, UK: Cambridge Scholars Publishing. 
Jewitt, C., Bezemer, J., \& O'Halloran, K. (2016). Introducing multimodality. Routledge.

Kachru, B. B. (1992). World Englishes: Approaches, issues and resources. Language teaching, 25(1), 1-14. Available on: https://doi.org/10.1017/S0261444800006583

Kress, G., \& Van Leeuwen, T. (2006). Reading images: The grammar of visual design. Routledge. London, UK.

Kress, G. (2010). Multimodality. London: Routledge.

Kuck, M. H. (2007). Mi and myself: Dual identity in Jamaican contact language speakers (Jamaica). In H. M. McGarrell (Ed.), Language Teacher Research in the Americas, (pp. 113-124). Alexandria, VA: TESOL.

Kutz, I. (2004). From outsider to insider: Studying academic discourse communities across the curriculum. In Zamel, V. \& Spack, R. (Eds.), Crossing the Curriculum: Multilingual learners in college classrooms (pp. 75-94). Mahwah, NJ: Lawrence Erlbaum.

Machin, D. \& Mayr, A. (2012). How to Do Critical Discourse Analysis A Multimodal Introduction. Sage.

Meschede, N., Fiebranz, A., Möller, K. and Steffensky, M. (2017). Teachers' professional vision, pedagogical content knowledge and beliefs: On its relation and differences between pre-service and in-service teachers. Teaching and teacher education, 66, 158-170. https://doi.org/10.1016/j.tate.2017.04.010

Norris, S. (2019) Systematically working with multimodal data: Research methods in multimodal discourse analysis. John Wiley \& Sons.

Null, W. (2016). Curriculum: From theory to practice. Rowman \& Littlefield.

Paik, K. (2018). The English language in Korea: its history and vision. Asian Englishes, 20(2), 122-133. https://doi.org/10.1080/13488678.2018.1426216

Pennycook, A. (2008). Critical Applied Linguistics: A Critical Introduction. Taylor \& Francis e-library, Kindle edition.

Rabbidge, M. (2017). Embracing reflexivity: the importance of not hiding the mess. TESOL Quarterly, 51(3). https://doi.org/10.1002/tesq.397

Richards, J. C. (2001). The role of textbooks in a language program. Cambridge University Press.

Rogan, J. M. (2007). How much curriculum change is appropriate? Defining a zone of feasible innovation. Science Education, 91, 439-460. Available on: https://doi.org/10.1002/sce.20192

Saslow, J. M. and Ascher, A. (2011). Top Notch: Student book 2. Pearson Longman.

Scollon, R., Scollon, S.W., \& Jones, R.H. (2011). What is a discourse approach? Intercultural communication: A discourse approach, 1-25.

Song, H. (2013). Deconstruction of cultural dominance in Korean EFL textbooks. Intercultural Education, 24(4), 382-390. Available on: https://doi.org/10.1080/14675986.2013.809248 
Stoller, A. (2015). Taylorism and the logic of learning outcomes. Journal of Curriculum Studies, 47(3), 317-333. Available on: https://doi.org/10.1080/00220272.2015.1018328

Thompson, A. S. and Lee, J. (2018). The motivational factors questionnaire in the Korean EFL context: Predicting group membership according to English proficiency and multilingual status. The Language Learning Journal, 46(4): 398-414. https://doi.org/10.1080/09571736.2015.1130082

Tomlinson, B., \& Masuhara, H. (Eds.). (2011). Research for materials development in language learning: Evidence for best practice. Bloomsbury Publishing.

Van Dijk, T. A. (Ed.). (1997). Discourse as social interaction (Vol. 2). Sage.

Van Dijk, T. A. (Ed.). (2011). Discourse studies: A multidisciplinary introduction. Sage.

Vygotsky, L. (1978). Interaction between learning and development. Readings on the development of children, 23(3), 34-41.

Weninger, C., \& Kiss, T. (2013). Culture in English as a foreign language (EFL) textbook: A semiotic approach. TESOL quarterly, 47(4), 694-716. Available on: https://doi.org/10.1002/tesq.87

Wodak, R., \& Meyer, M. (2016). Methods of Critical Discourse Studies. SAGE Publications. Kindle Edition.

Wohlwend, K. E. (2011). Mapping modes in children's play and design: An actionoriented approach to critical multimodal analysis. An introduction to critical discourse analysis in education, 242-266.

Woods, D. (1996). Teacher Cognition in Language Teaching. Cambridge University Press.

\section{Contact}

Christopher A. Smith, PhD.

University of Western Ontario

London, Ontario

Canada

csmit655@uwo.ca 